\title{
Numerical analysis of a three dimensional fluid flow in a flat plate solar collector
}

\author{
Amraoui. M. A., Aliane. K. \\ Department of Mechanical Engineering, Faculty of Technology, University of Tlemcen, Tlemcen, Algeria \\ Email address: \\ amraoui_mohammedamine@yahoo.fr(Amraoui. M. A.), kh_aliane@yahoo.f (Aliane. K.)
}

\section{To cite this article:}

Amraoui .M. A., Aliane. K.. Numerical Analysis of a Three Dimensional Fluid Flow in a Flat Plate Solar Collector. International Journal of Renewable and Sustainable Energy. Vol. 3, No. 3, 2014, pp. 68-75. doi: 10.11648/j.ijrse.20140303.14

\begin{abstract}
Flat plate solar collectors are the most common thermal collectors used among the various solar collectors for domestic and industrial purposes. The objective of this study is to perform computational fluid dynamics (CFD) simulation of flat plate collector with air flow. In this paper, the CFD tool has been used to simulate the solar collector for better understanding of its heat transfer capability. Using a 3D model of the collector involving air inlet, the collector is modeled by ANSYS Workbench and the grid was created in ANSYS ICEM. The results were obtained by using ANSYS FLUENT. The objective of this work is to compare theoretical and experimental achieved work toward the given work by using CFD tool with respect to flow and temperature distribution inside the solar collector. The outlet temperature of air was compared with experimental results and there was a good agreement between them.
\end{abstract}

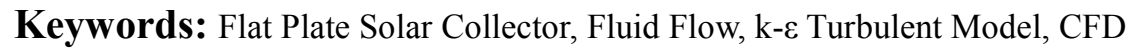

\section{Introduction}

Solar collectors are key components of active solar-heating systems. They gather the sun's energy, transform its radiation into heat and then transfer that heat to a fluid (usually water or air). The solar thermal energy can be used in solar water-heating systems, solar pool heaters, and solar space-heating systems.

Mahfoud et al. [1] presents a numerical simulation on air flow and heat transfer characteristics in solar air collectors mounted with obstacles. In this study, Computational Fluid Dynamics, based on the finite volume method, SIMPLE algorithm and the turbulence standard $(\mathrm{k}-\varepsilon)$ model have been implemented. A numerical 2D model of dynamic air vein solar collectors with $1400 \mathrm{~mm}$ length and $25 \mathrm{~mm}$ air gap was used in [1] to evaluate hydrodynamic and heat transfer phenomena of flow patterns in the annular passageways, precisely the heat transfer around 13 chicanes. The chicane is formed with two parts: the first is perpendicular to the air flow and the second is tilted $\left(\alpha=60^{\circ}\right)$, they are mounted in successive rows, oriented perpendicular to the air flow. It is apparent that the turbulence created by the chicanes resulted in greater increase in heat transfer over the air vein. The pressure drops are analyzed via the Reynolds number and showed good agreements with experimental and semi-empirical relationship results. The mass flow rates effect on the velocity magnitude is also analyzed. It was found that the mass flow rate variation has a slight effect on the velocity evolution.

Yadav et al. [2] presents the study of heat transfer in a rectangular duct of a solar air heater having triangular rib roughness on the absorber plate by using CFD. The effect of Reynolds number and Nusselt number was investigated. The computations based on the finite volume method with the SIMPLE algorithm have been conducted for the air flow in terms of Reynolds numbers ranging from 3000-18000. A commercial finite volume package ANSYS FLUENT 12.1 was used to analyze and visualize the nature of the flow across the duct of a solar air heater. CFD simulation results were found to be in good agreement with experimental results and with the standard theoretical approaches. It was been found that the Nusselt number increases with increase in Reynolds number.

In the study by Satya Prakash Nayak [3], CFD software was used to perform a numerical simulation for enhance turbulent heat transfer. A present CFD analysis of heat transfer and flow pattern with artificial roughness in the form of different types of ribs, heated wall of rectangular duct for turbulent flow with Reynolds number range (3000-15000) and for the ratio of length to height of the rib $\mathrm{p} / \mathrm{e}$ (5 to 20 ) was carried out. The $\mathrm{k}-\omega$ turbulence model was selected by comparing the predictions of different 
turbulence models with experimental results available in various literatures. This study evaluates reattachment point, heat transfer and fluid flow behavior in a rectangular duct with different roughened ribs mounted on one of the principal wall (solar plate) using the CFD software (Fluent 6.3.26 Solver). The results are validated by comparing with existing experimental data. The analysis shows that peak in local heat transfer occurs at the point of reattachment of the separated flow as observed experimentally. The normalized friction factors in a square duct roughened with various-shaped ribs at the same pitch ratio $(\mathrm{p} / \mathrm{e}=12)$. In the given Reynolds number range, the trapezoidal-shaped ribs have the highest friction loss; whereas, the trapezoidal-shaped ribs have the lowest pressure drop. Furthermore, the triangular-shaped ribs have slightly higher friction factor than that of the square-shaped ribs based on the law of the wall.

The study by Prashant Baredar et al. [4] evaluates heat transfer and fluid flow behavior in a rectangular duct with inverted U-type turbulator roughened ribs mounted on one of the principal wall (solar plate) using CFD software (Fluent 6.3.26 Solver). In this study, the CFD software was used to perform a numerical simulation for enhanced turbulent heat transfer. In this study, the Reynolds-Averaged Navier-Stokes analysis was used as a numerical technique and the k- $\varepsilon$ turbulent model with near-wall treatment as a turbulent model. The results are validated by comparing with existing experimental data. A thin inclined U-turbulator geometry with a passage underside could definitely prevent totally the formation of eddies and also the redevelopment of two boundary layers at the reattachment point between two adjacent ribs. The value of the Nusselt number increases sharply at low Reynolds number and this becomes constant or increases very slightly in comparison to low Reynolds number. This also satisfied our aim of solar collector application at low Reynolds number.

One key problem of using solar energy is low heat exchange between the coolant and absorber of the solar collector. On the other side, the introduction of baffle (obstacles) arranged in ducts rows of these systems greatly improves heat transfer. Aliane et al. [5] study the roughness influence at the insulation to increase thermal exchanges within the collector. A numerical study using finite volume methods is performed to represent the dynamics and the thermal behavior of airflow in a solar collector plane with and without baffles with rectangular roughness. Regarding the temperature fields, and for the case without roughness, the temperature becomes immediately downstream high of the second baffle. As against, for the case with roughness, temperature is progressive and significant from the first baffle values.

The existence of the obstacle in a flow certainly causes recirculation zone located upstream and downstream of the obstacle. These zones may represent pollution areas, where the pollution remains retained. Sari-hassoun et al. [6] propose a model of the obstacle which reduces these zones. A qualitative study of the flow around the obstacle have given a good idea of the behavior's recirculation zone. They used the upstream edge and adapted a bright obstacle to the form of the recirculation zone appearance and observed the reduction in this recirculation zone.

The work of Aliane [7] presents the numeric analysis of the turbulent flow inside a channel of rectangular section, with two types of obstacles, a rectangular block obstacle, and a rectangular obstacle with upstream round edge with a radius curvature of 0.2 times the height of the obstacle. This is an important problem in the scope of electronics cooling and heat exchanger, where the characterization of the flow, velocity distribution, as well as the existence and the extension of possible recirculation zones need to be identified. The objective of [7] is to compare the special round obstacle impacts on the recirculation zone and velocity profiles considering those of the rectangular block obstacle.

It has been recently proposed by several investigators that provision of artificial roughness on the underside of absorber plate could substantially enhance the heat transfer rate of a solar air heater. Prasad and Saini (1988) [8] investigated fully developed turbulent flow in a solar air heater duct with a small diameter protrusion wire on the absorber plate. Gupta et al. (1997) [9] used continuous ribs of inclination $60^{\circ}$ and they optimized thermo-hydraulic performance. They found that the optimum operating flow rate shifted to a lower value as the relative roughness height increases. Karwa et al. (1999) [10] used chamfered rib roughness on the absorber plate and they found that at low flow rate, the solar air heater with roughness elements having a higher relative roughness height yields a better performance. An extensive investigation of heat transfer and fluid flow in solar air heater ducts with metal rib grits on absorber plate at $60^{\circ}$ angle of attack has been conducted and the correlations are developed by Karmare and Tikakar (2007) [11]. The thermal and thermo-hydraulic performance of this solar air heater is also carried out by Karmare and Tikakar (2009) [12]. Karmare et al. [13] presents a study of fluid flow and heat transfer in a solar air heater by using CFD, which reduces time and cost. In this analysis collector plate is made rough with metal ribs of circular, square and triangular cross-section, having $60^{\circ}$ inclination to the air flow. The grit rib elements are fixed on the surface in staggered manner to form defined grid. To validate CFD results, experimental investigations were carried out in the laboratory. The experimental results of the roughened solar air heater are compared with CFD analysis results. The square cross-section ribs with $58^{\circ}$ angle of attack gives a maximum heat transfer. The percentage enhancement in the heat transfer for square plate over smooth surface is $30 \%$.

Chongjie Wang et al. [14] analyzed the performance characteristics of the unglazed transpired solar air collector and compared them with several kinds of traditional solar air collectors. The results showed that the unglazed transpired solar air collector has unparalleled advantages in the ventilation preheating area. The results showed that the unglazed transpired solar air collector has unparalleled 
advantages in the ventilation preheating area and also proves that CFD tools have their own advantages in the solar air collector research area.

The equipment for the experimental research into the materials of solar collectors was built in the research laboratory for research purposes in 2005, Palabinskis et al. [15]. The construction of the equipment allows for simultaneous comparative studies of two materials. The experimental data are metered and recorded in the electronic equipment REG. Cell polycarbonate PC (bronze, henceforth referred to as polycarbonate) with absorbers steel-tinplate and black-coloured wood was studied in comparison to the polyvinylchloride film (henceforth referred to as a film). The research was made with different air velocities. The air heating degree $\Delta \mathrm{T}$ in the solar collector is dependent on solar radiation $I$ and air velocity $v$ in the solar collector. In the experimental equipment, which is 1.5 meters in length, the air was heated to $\Delta \mathrm{T}=6^{\circ} \mathrm{C}$ at the velocity $v=0.5 \mathrm{~ms}^{-1}$. For theoretical investigation of the air heating power in solar systems the mathematical model is applied; the solution can be used for estimation of different materials (absorbents) and their heat source.

Kumar et al. [16] studied the behavior of solar air heater with and without porous media and also to compare their performance under different set of conditions, obtained by changing various governing parameters like air mass flow rate, inlet air temperature, spacing between top cover and absorber plate and intensity of solar radiation. The problem was solved using the finite difference method. They presented the mathematical model for predicting the heat transfer characteristics and the performance of solar air heater with and without porous media. The solar air heater with porous media gives higher thermal efficiency than without porous media. The thermal conductivity of porous media has significant effect on the thermal performance of the solar air heater. The work has been carried out using GAMBIT and FLUENT software as the standard tool for flow analysis and widely acceptable. A double pass flat plate solar air heater model is subjectely prepared to the relative loads, constraints and results are obtained for the proposed models.

This paper presents the study of fluid flow and heat transfer in a solar air heater by using CFD, which reduces time and cost. However, for solar air collectors, heat transfer is low. In this paper, we show the design of air collector on which it is possible to improve the heat transfer between the absorber and the airflow to favor the energetic efficiency, while assuring a maximum increase of temperature. We introduced baffles by using simulation. We observed the formation of a meandering flow. In this case, it is clear that the length of the trajectory is more double than that of the collector, thus increasing the air speed and the heat transfer. On the other hand, the size of the dead zones is considerable.

\section{Materials and Methods}

\subsection{Geometry}

The model for the solar collector has already been studied experimentally by [17]. The air flow moves between the insulation and the absorber, with two types of baffles.

The first type consists of six baffles arranged in a labyrinth, have rectangular shape, and they have the same height as the air passage. They are arranged transversally to the insulation. They occupying $80 \%$ of collector width (see Figure 1).

To cure the problem of the large dead zones, longitudinal baffles are introduced, which does not touch the absorber and extends the flow and reduces the dead zones to a minimum. This is shown in Figure 1. The efficiency is very much increased. The dimensions are as follow:

- Length the collector $(\mathrm{L})=2000 \mathrm{~mm}$;

- Width the collector $(1)=1000 \mathrm{~mm}$; and

- Height of the flow path $=25 \mathrm{~mm}$.

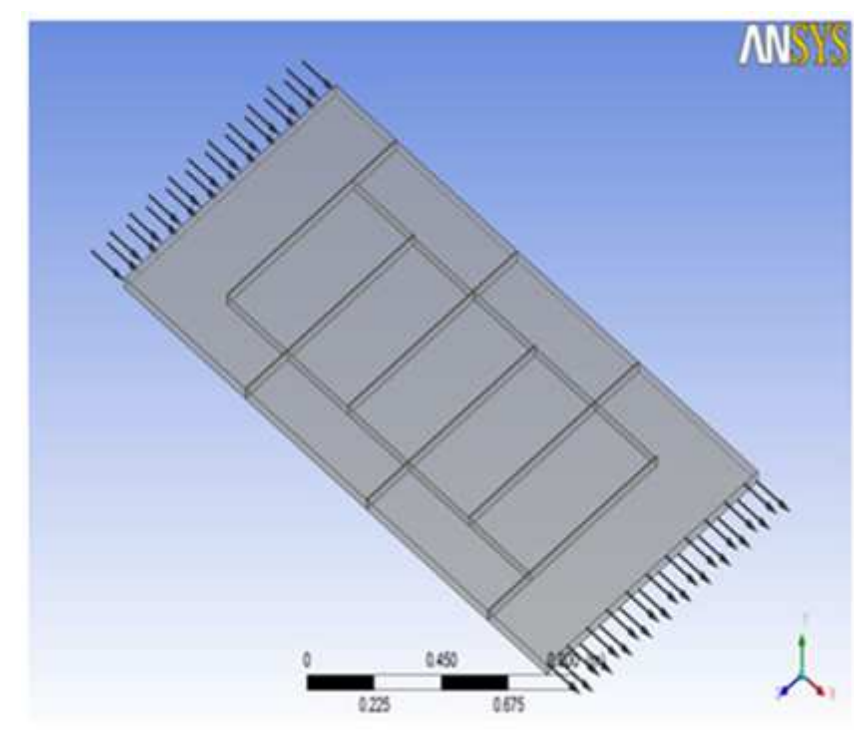

Figure 1. Sketch for the solar collector 2.2. Mesh

There was a need to place very fine mesh near the ribs to predict the results accurately: see Figures 2 and 3.

Meshing of the domain was done using ANSYS, with non-uniform quad grid of $1 \mathrm{~mm}$ grid size. This size was suitable to resolve the laminar sub-layer. A general practice is to use fine mesh size in the area where greater details are desired such as fins and coarse mesh in areas of small changes in geometry domain. Non-uniform high density mesh in inter fin region and on edges and corners were employed while low density mesh was adapted in the smooth wall regions. This helped in economizing the number of cells needed for acceptable computational time and computer memory. Figure 2 and 3 shows the grid pattern for the flow domain. 


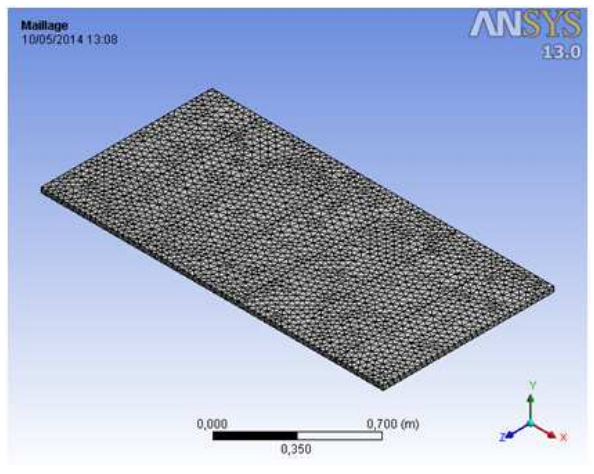

Figure 2.3D mesh of solar flat plate collector

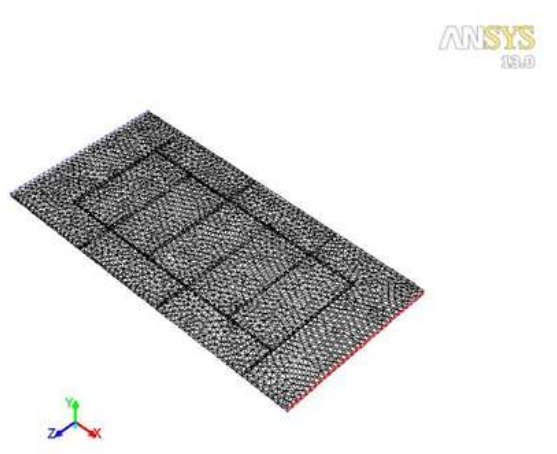

Figure 3. Flow domain with baffles arranged transversely and small baffles

\subsection{The Boundary Conditions}

As the flow is turbulent, $\mathrm{k}-\varepsilon$ model is selected as turbulent model for further analysis of the problem. No slip condition is applied to all the 'walls'. The physical aspects of any fluid flow are governed by the fundamental principles: Continuity Equation (conservation of mass), Momentum Equation (Newton's Second Law of Motion), and conserved energy. To solve these equations, under-relaxation factors are used:

-The velocity of the air at the inlet: $\mathrm{u}_{0}=0.0138 \mathrm{~m} / \mathrm{s}$ with a corresponding rate flow of $50 \mathrm{~m}^{3} / \mathrm{hm}^{2}$.

-The air temperature at the inlet $\mathrm{T}_{\mathrm{e}}=300 \mathrm{~K}$

-The turbulent kinetic energy at inlet $k=0.005, \mathrm{U}_{0}{ }^{2}=$ $9.645 \times 10^{-7} \mathrm{~m}^{2} / \mathrm{s}^{2}$

-The energy dissipation at inlet $\varepsilon=0.1, k^{2}=9.3 \times 10^{-14}$ $\mathrm{m}^{2} / \mathrm{s}^{3}$

-The temperature of the absorber: $\mathrm{T}_{\mathrm{abs}}=380 \mathrm{~K}$

-The temperature of the insulation and the lower baffle: $\mathrm{T}_{\text {iso }}=340 \mathrm{~K}$ and

-The outlet pressure: $\mathrm{P}_{\mathrm{s}}=\mathrm{P}_{\mathrm{atm}}$.

\section{Discussions and Interpretations}

The results obtained from the CFD analysis of the solar flat plate collector are presented in this section. The simulation was carried out for different flows. The results obtained by this simulation are compared with the experimental results as shown in Table 1. The difference between the experimental and simulated outlet temperature for the different flows is about $4^{\circ} \mathrm{C}$.
Table 1. Comparison of experimental and CFD results

\begin{tabular}{ccc}
\hline Flow $\mathbf{~ m}^{3} / \mathbf{h m}^{2}$ & $\begin{array}{l}\text { Collector } \Delta \mathrm{T} \text { by CFD } \\
\text { (Own) results }\left({ }^{\mathbf{0}} \mathbf{C}\right)\end{array}$ & Collector $\Delta \mathrm{T}$ [17] $\left.\mathbf{(}^{\mathbf{0}} \mathbf{C}\right)$ \\
\hline $\mathrm{Q} 1=50$ & 49 & 53 \\
$\mathrm{Q} 2=35$ & 63 & 67 \\
\hline
\end{tabular}

\subsection{Temperature Field}

The temperature distribution is obtained by CFD simulation. The contour plots obtained for the temperature distribution is given by Figure 4.

As air passes above the absorber, the heat exchange takes place from the surface to air. The air very close to the surface gets heated due to convection. This primary hot layer mixes with the secondary cold air using baffles, and heat transfer takes place due to conduction and convection. As a result, the temperature of air close to the surface is higher, and goes on decreasing away from the surface up to one third the height of the duct.

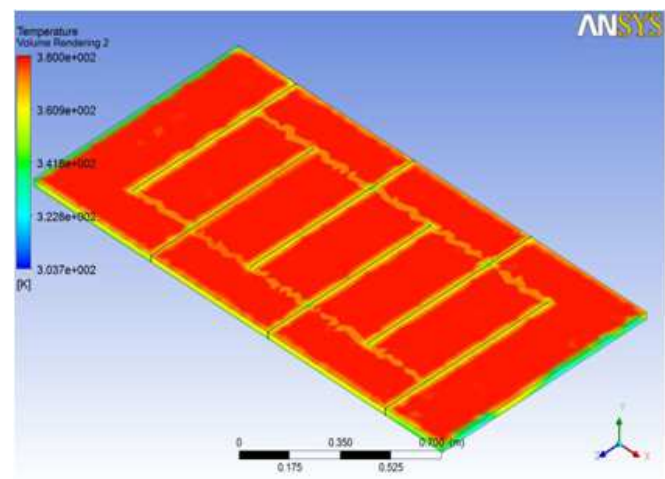

Figure 4. Temperature field for the collector

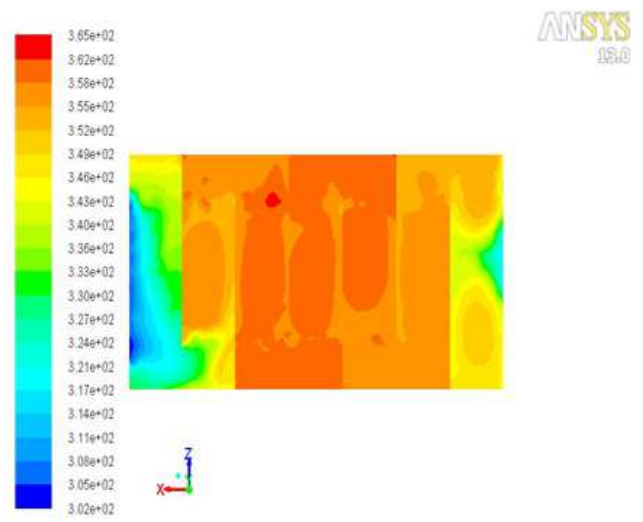

Figure 5. Temperature field (plane $X, Z$ )

Figure 5 shows the distribution of the temperature field for a cross section in the plane X, Z. At the entrance, the air has a temperature of $300 \mathrm{~K}$, which begins to apply heat across half the distance between the inlet and the first transverse baffle which reaches a temperature of $362 \mathrm{~K}$, by passing the latter, which reaches a temperature of about 350 $\mathrm{K}$. In conclusion it follows that, the flow of air keeps the same temperature $(350 \mathrm{~K})$, as they cross the rows of baffles until exit. 


\subsection{The Velocity Vector $V$}

Figure 6 shown that the longitudinal baffles increase the air velocity. On the other hand, the size of the dead zones is considerable.

To solve the problem of the large dead zones, we introduced longitudinal baffles, which extends the flow and reduces the effect of the dead zones to a minimum. The efficiency is very much increased.

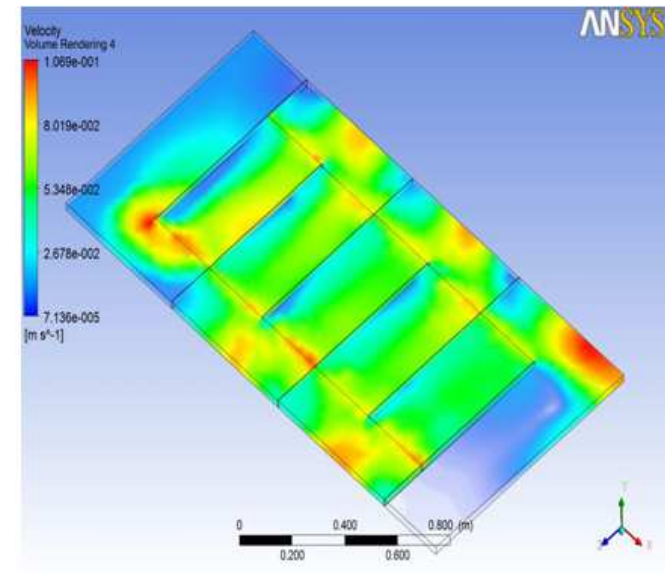

Figure 6. Velocity distribution

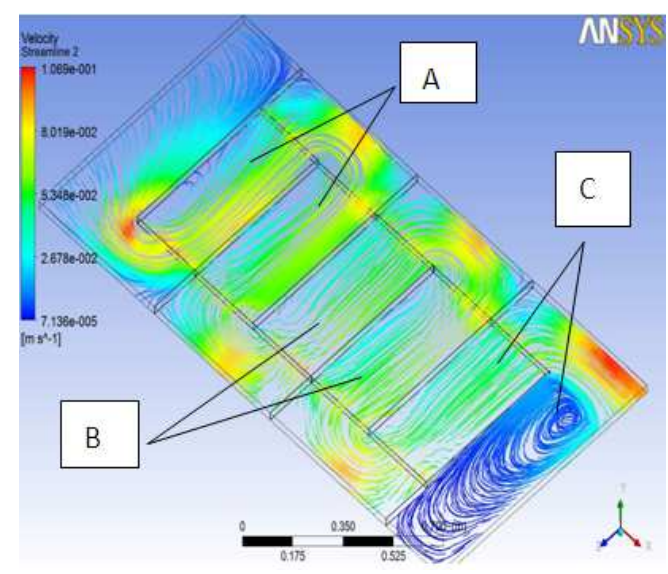

Figure 7. Streamlines for velocity distribution

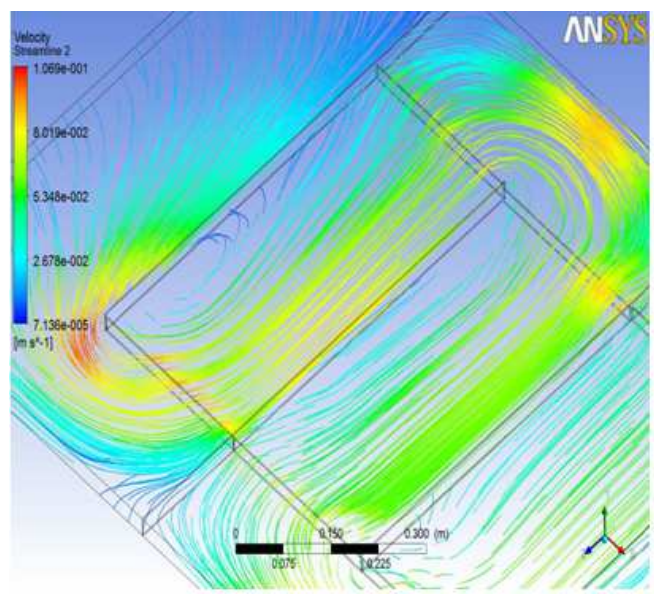

Figure 8. Streamlines for velocity distribution (area A)
Figures 7, 8, 9 and Figures 10 shows the streamlines for velocity distribution around transverse and longitudinal baffles. Figure 7 shows that the streamlines are very close together around the small baffles which accelerate the flow in these places. This is due to the narrowing of the passage section. However, the transverse baffles promote the occurrence of undesirable recirculation zones.

Figures 8, 9 and 10 show that the velocity is very important in the areas where there are longitudinal baffles which do not touch the absorber.

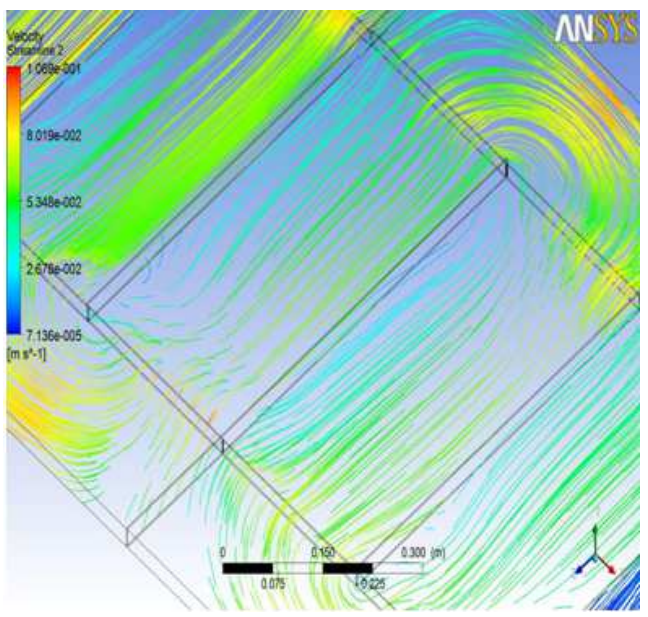

Figure 9. Streamlines for velocity distribution (area B)

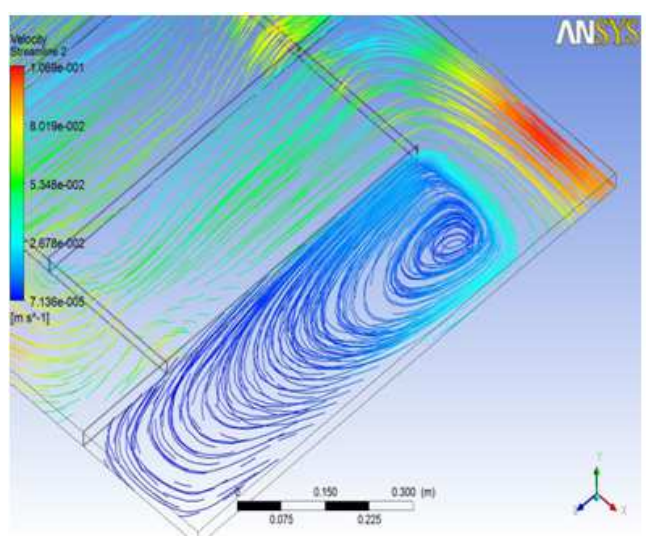

Figure 10. Streamlines for velocity distribution (area C)

\subsection{The Velocity Components}

The three velocity components are given by Figures 11, 12 and 13. Velocity component $u$ (figure 11) is very important in the lateral sides of the solar collector $(7$ times greater than the input velocity). Otherwise, the center, has a value twice greater than the entered velocity. Concerning the v component (Figure 12), this is almost the same velocity throughout the air flow with the exception of the above longitudinal baffles. The velocity component w (figure 13) varies substantially in the labyrinth by taking positive values (in the same direction of the $\mathrm{z}$ axis) and negative values (opposite direction of the $\mathrm{z}$ axis). 


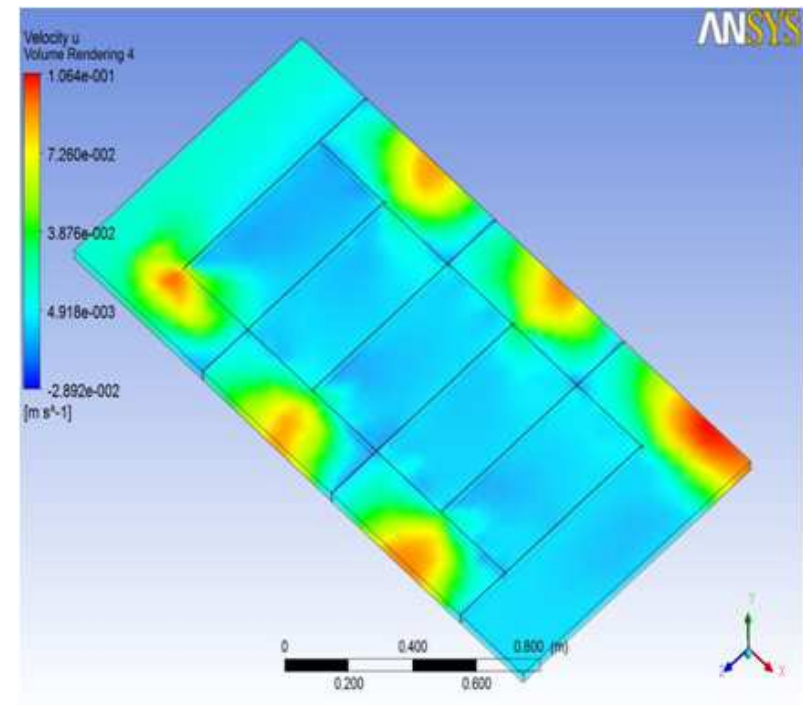

Figure 11. The velocity component $u$

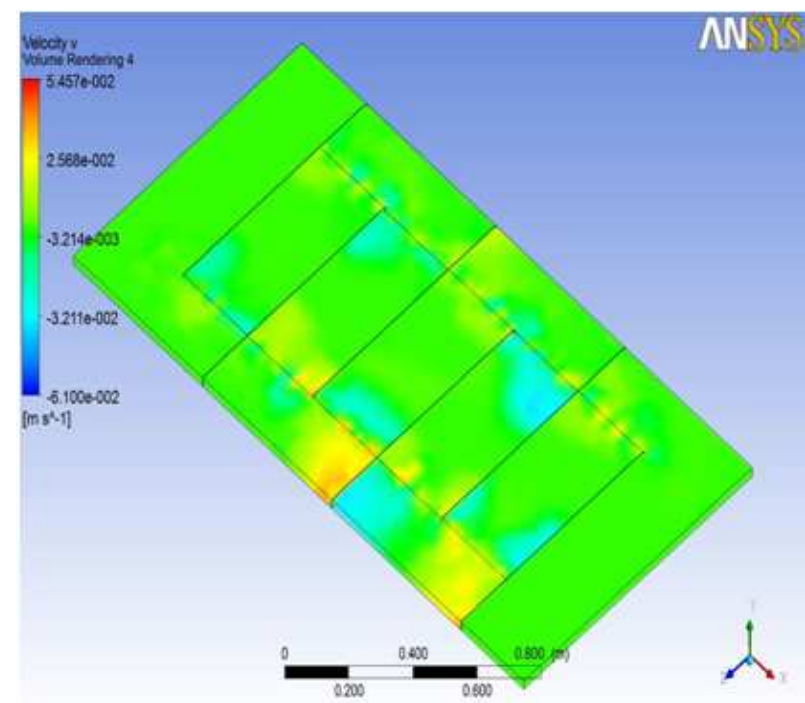

Figure 12. The velocity component $v$

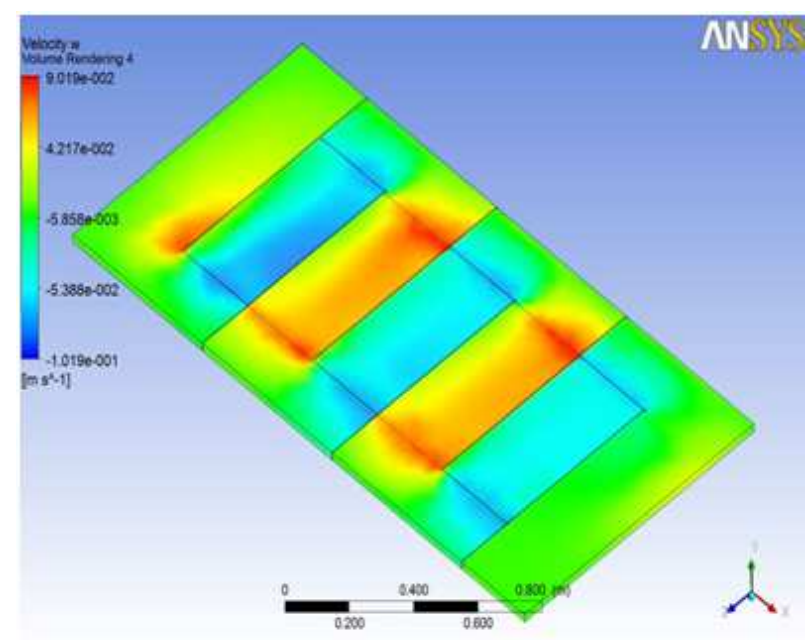

Figure 13. The velocity component $w$

\subsection{Turbulent Kinetic Energy (k)}

The distribution of turbulent kinetic energy ( $k$ ) is given by Figure 14. It is clear that the flow has a turbulent kinetic energy throughout their trajectory. There is a considerable increase of turbulent kinetic energy in the longitudinal baffles.

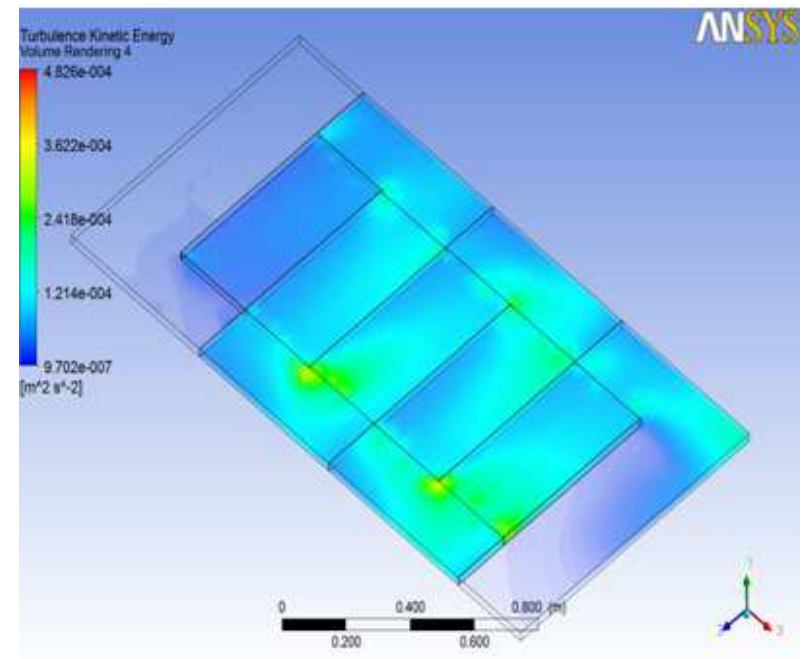

Figure 14. Turbulent kinetic energy $(k)$

\subsection{Turbulent Eddy Dissipation (ع)}

Turbulent eddy dissipation $(\varepsilon)$ is given in Figure 15. We find that, the dissipation is very important going around the longitudinal baffles.

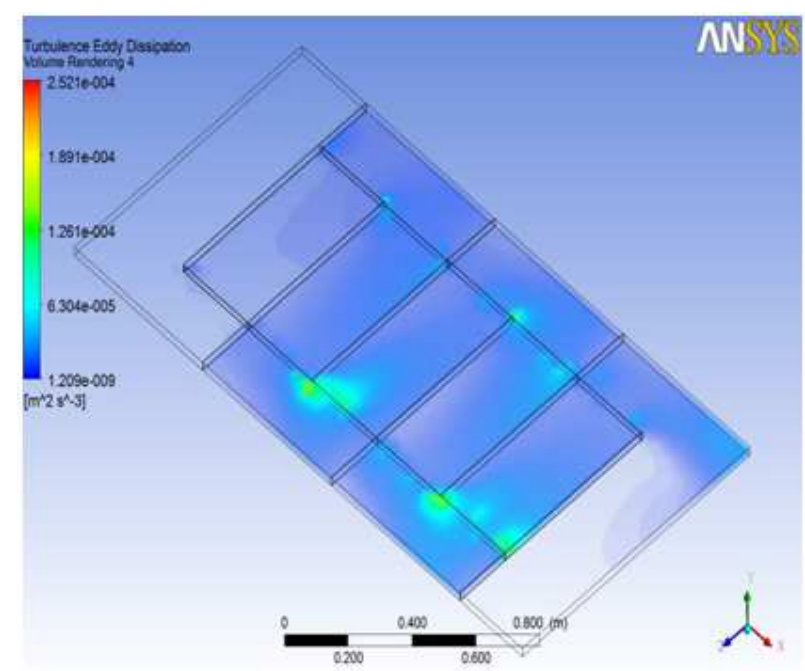

Figure 15. Turbulent eddy dissipation $(\varepsilon)$

\subsection{Turbulent kinetic energy (k) profiles}

The different profiles are drawn in the area " $C$ " and between the insulation and the absorber. The turbulent kinetic energy $(\mathrm{k})$ is very important in the region with longitudinal baffles compared to the region without longitudinal baffles, see Figure 16. 


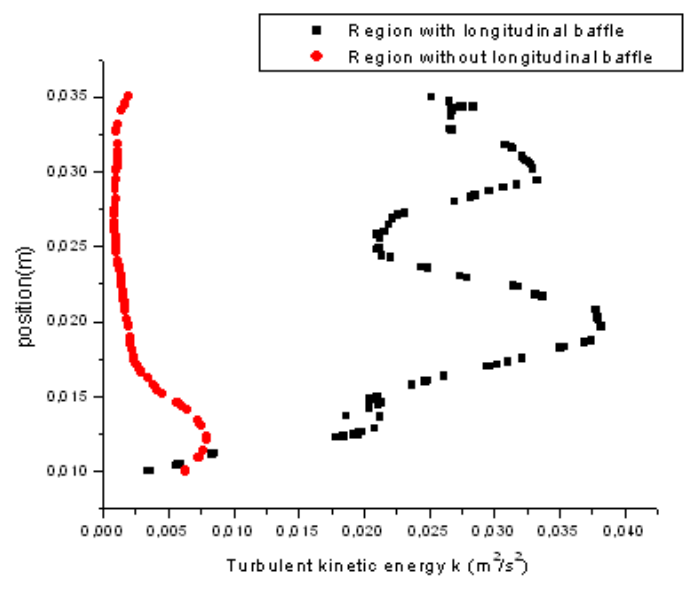

Figure 16. Turbulent kinetic energy (k) profiles

\subsection{Turbulent Eddy Dissipation (c) Profiles}

The turbulent eddy dissipation $(\varepsilon)$ is very important in the region with longitudinal baffles compared to the region without longitudinal baffles, see Figure 17.

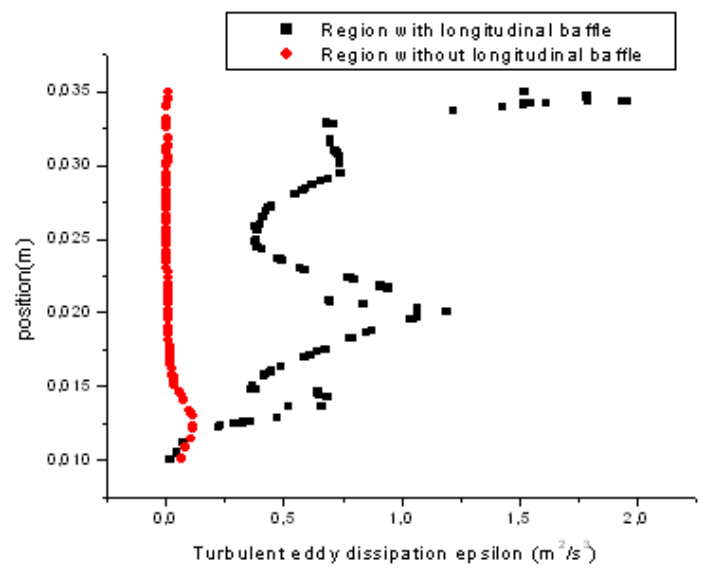

Figure 17. Turbulent Eddy dissipation (c) profiles

\subsection{Velocity Profiles}

The velocity profiles are similar except for the position $(0.02$ to $0.022 \mathrm{~m})$, where the velocity of the longitudinal baffle region in this position reaches $0.73 \mathrm{~m} / \mathrm{s}$, see Figure 18 .

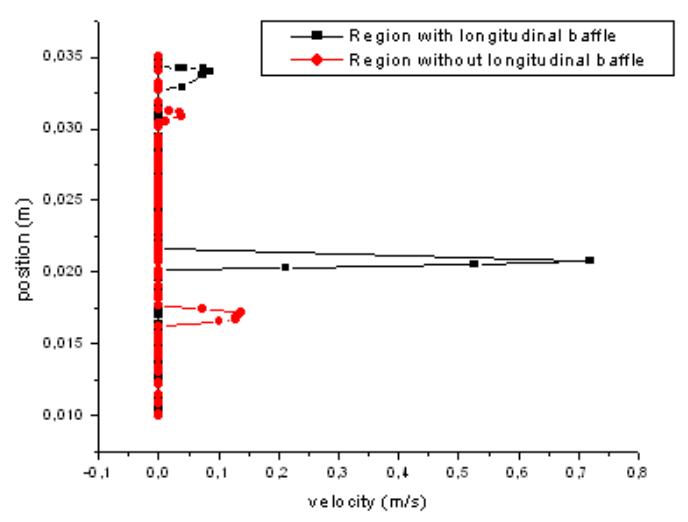

Figure 18. Velocity profiles

\subsection{Velocity Profiles}

The temperature is very important in the region with longitudinal baffles compared to the region without longitudinal baffles, see Figure 19.

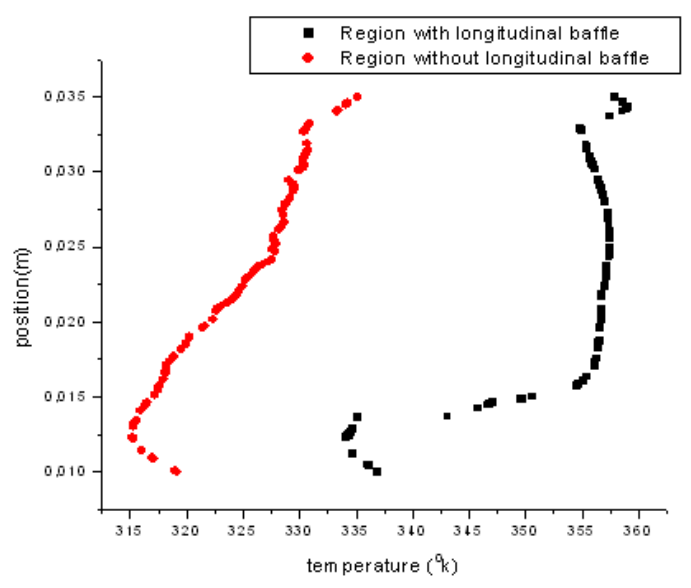

Figure 19. Temperature profiles

\section{Conclusion}

To solve the problem of the large dead zones, we introduced longitudinal baffles, which did not touch the absorber and which extended the flow and reduced the effect of the dead zones to a minimum. The efficiency increased very much. These baffles, placed in the air channel and which are situated between the insulator and the absorber, have the particularity of the trajectory extending circulation. This leads to a constant contact between the air and the absorber. These baffles thus serve the role of the fins and improve the heat transfer within the solar collector.

There is a good agreement between the experimental and simulated results for the outlet air temperature, although there are discrepancies due to experimental errors. We have good confidence in the CFD simulation program which can be used in the future for more complex solar collector problems.

\section{References}

[1] Mahfoud, O., M. Zedayria, A. Moummi and N. Moummi, "Numerical 2D study of air flow controlled by active technique in solar air collector," Revue des Energies Renouvelables, Vol. 16 ,N 1, 159 - 170, 2013.

[2] Anil Singh Yadav, J. L. Bhagoria, "A CFD Analysis Of A Solar Air Heater Having Triangular Rib Roughness On The Absorber Plate," International Journal of ChemTech Research, Vol.5, No.2, pp 964-971, April-June 2013

[3] Satya Prakash Nayak , Priti Shukla, Satyashree Ghodke, "CFD Analysis of Solar Flat Plate Collector Heat Transfer and Fluid Flow Analysis of Roughness Rib in Solar Air Heater Duct by Computational Fluid Dynamics (CFD) Simulation," International Journal of Advanced Research in Science, Engineering and Technology,Vol.01, Issue 03, pp. 15- 20, 2012 
[4] Prashant Baredar, Shankar Kumar, Ajeet Kumar Giri and Jitendra Kumar, "Heat transfer and fluid flow analysis of roughness ribin solar air heater duct by computational fluid dynamics (CFD)," Current World Environment, Vol. 5(2), 279-285, 2010.

[5] Aliane, K., M.A. Amraoui, "Etude numérique d'un capteur solaire plan à air ayant une rugosité rectangulaire," Revue des Energies Renouvelables, Vol. 16, N 1, 129 - 141, 2013.

[6] Sari-hassoun, Z., K. Aliane, O. Sebbane, “ Numerical simulation study of the structure of the separated flow around obstacles: curved edge effect," International Journal on Heat and Mass Transfer - Theory and Applications (IREHEAT), Vol. 1, n. 5,October 2013.

[7] Aliane, K., "Passive control of the turbulent flow over a surface-mounted rectangular block obstacle and a rounded rectangular obstacle," International Review of Mechanical Engineering (I.R.E.M.E.), Vol. 5, n. 2, February 2011.

[8] Prasad, B. N., Saini, J. S., "Effect of artificial roughness on heat transfer and friction factor in solar air heater," Solar Energy, 41, 555-560, 1988.

[9] Gupta, D., Solanki, S. C., Saini, J. S, "Thermo hydraulic performance of solar air hearers with roughened absorber plates," Solar Energy, 61, 33-42., 1997.

[10] Karwa, R., Solanki, S. C., Saini, J. S., "Heat transfer coefficient and friction factor correlation for the transitional flow regime in rib roughened rectangular ducts," Int. J. Heat Mass Transfer, 42, 1597-1615, 1999.
[11] Karmare, S. V., Tikakar, A. N, Heat transfer and friction factor correlation for artificially roughened duct with metal grit ribs, Int. J. Heat Mass Transfer, 50, 4342-4351, 2007.

[12] Karmare, S. V., Tikakar, A. N, "Experimental investigation of optimum thermo hydraulic performance of solar air heaters with metal rib grids roughness," Int. J. Solar Energy, 83, 6-13, 2009.

[13] Karmare, S. V., A. N. Tikekar, "Analysis of fluid flow and heat transfer in a rib grit roughened surface solar air heater using CFD, Solar Energy, 84 (2010) 409-417

[14] Chongjie Wang, Zhenzhong Guan, Xueyi Zhao, Delin Wang, "Numerical Simulation Study on Transpired Solar Air Collector," Renewable Energy Resources and a Greener Future, Vol. VIII-3-4, 2006.

[15] Palabinskis, J., A. Aboltins, A. Lauva and N. Karpova-Sadigova, "The comparative material investigations of solar collector," Agronomy Research, 6 (Special issue), 255-261, 2008.

[16] Anup Kumar, Anil Kumar Mishra, "A CFD Investigation and Pressure Correlation of Solar Air Heater," International Journal of Mechanical Engineering and Technology (IJMET), Volume 4, Issue 2, pp. 401-417, March - April 2013.

[17] Ben Slama Romdhane, "The air solar collectors Comparative study, introduction of baffles to favor the heat transfer," Solar Energy, 81, 139-149, 2007. 